\title{
Ectopic Adrenal Gland in Mesosalpinx: A Case Report and Literature Review
}

\author{
Yanjing Wang ${ }^{\dagger}$ Bingjuan Zhou', Xu Wang, Jinku Zhang* \\ Key Laboratory of Molecular Pathology and Early Diagnosis of Tumor in Hebei Province; Pathology Department of \\ Baoding First Central Hospital of Hebei Province, Hebei Province, China \\ ${ }^{\dagger}$ These authors contributed equally to this work \\ *Corresponding author: Jinku Zhang, 843561234@qq.com

\begin{abstract}
A case of ectopic adrenal gland tissue in mesosalpinx is reported. A 52-year-old patient was admitted to the hospital for irregular vaginal bleeding for 2 months. Ultrasound scan showed multiple hypoechoic masses in the myometrium of the anterior wall of uterus with regular shape and clear boundary. Laparoscopic hysterectomy and bilateral adnexectomy were performed. In the course of pathological diagnosis, we accidentally found ectopic adrenal gland tissue in the left mesosalpinx. We believe this is worthy of reporting since this case is rare.
\end{abstract}

Keywords: Ectopic adrenal tissue; Fallopian tube

Publication date: July 2021; Online publication: July 30, 2021

\section{Case presentation}

A 52-year-old female patient was admitted to the hospital for irregular vaginal bleeding for 2 months. Based on gynecological examination, the vulva and vagina were smooth. The cervix was also smooth and of normal size. The patient did not experience lifting pain. Anterior position of uterus was enlarged as if the patient was in the phase of 3 months of gestation. The surface was tough and there were a number of uneven myoma like protrusion with a range of motion and no tenderness. No mass or tenderness was found in bilateral appendages. Ultrasound scan showed that there were many hypoechoic masses in the myometrium of the anterior wall of uterus, with regular shape, clear boundary, and outward protruding direction. The masses had peripheral blood flow signals, and even echo in the other myometrium. No obvious abnormality was found in cervix and bilateral appendages. The patient underwent hysterectomy and bilateral adnexectomy based on the diagnosis of hysteromyoma. The postoperative specimens were sent for pathological examination.

The postoperative specimens were broken uterine tissue, with a measurement of $16 \times 9 \times 6 \mathrm{~cm}$. The diameter of the cervical canal was $3.5 \mathrm{~cm}$, the length of the cervical canal was $4 \mathrm{~cm}$, and the diameter of the cervical canal was $3.5 \mathrm{~cm}$. The inner membrane was not clear, and several nodular masses could be seen between the muscular walls and under the serosa. The smallest diameter of the masses was $2.5 \mathrm{~cm}$ and the largest size was $8.5 \times 6.5 \times 6 \mathrm{~cm}$. The section is solid, gray, white and tough. The left fallopian tube was $6.5 \mathrm{~cm}$ long and $0.5 \mathrm{~cm}$ in diameter, with a fimbria end. A vesicle with a diameter of $0.5 \mathrm{~cm}$ was found in the mesangium, containing cool liquid. Left ovary had a size of $2 \times 1 \times 5 \mathrm{~cm}$ in solid gray matter. The right fallopian tube was $6 \mathrm{~cm}$ long, $0.5 \mathrm{~cm}$ in diameter, with an umbrella-shaped end. A vesicle with diameter of $1 \mathrm{~cm}$ can be seen at the mesangium, containing cool liquid. The size of the right ovary was 4.5 $\times 2.5 \times 1 \mathrm{~cm}$ in solid gray matter.

In the course of carefully observing the section of the left fallopian tube, we happened to find nodules 
with a size of $2 \times 1.5 \mathrm{~mm}$. Microscopically, the border of the nodule was clear and consisted of three layers of adrenal cortex (Figure 1A). In the globular zone, the cells were small, columnar or cuboidal, arranged in pellets, with oval nuclei, dark coloration and weak basophilic cytoplasm (Figure 1B). In the fascicular zone, the cells were large, polygonal, arranged in cords and columnar, with oval nucleus and small nucleoli in the middle. The cytoplasm was weakly basophilic, with light staining and a large number of vacuoles (Figure 2A). In the reticular zone, the cells were smaller, round, reticular, granular and weakly eosinophilic (Figure 2B). The nodule was very similar to normal adrenal gland, but lacked medullary component. Immunohistochemistry was used and the results show that the tissues are positive for $\alpha$-inhibin (Figure 3A) and syn (Figure 3B). With these findings, we came up with the pathological diagnosis of ectopic adrenal cortex in the left mesosalpinx.

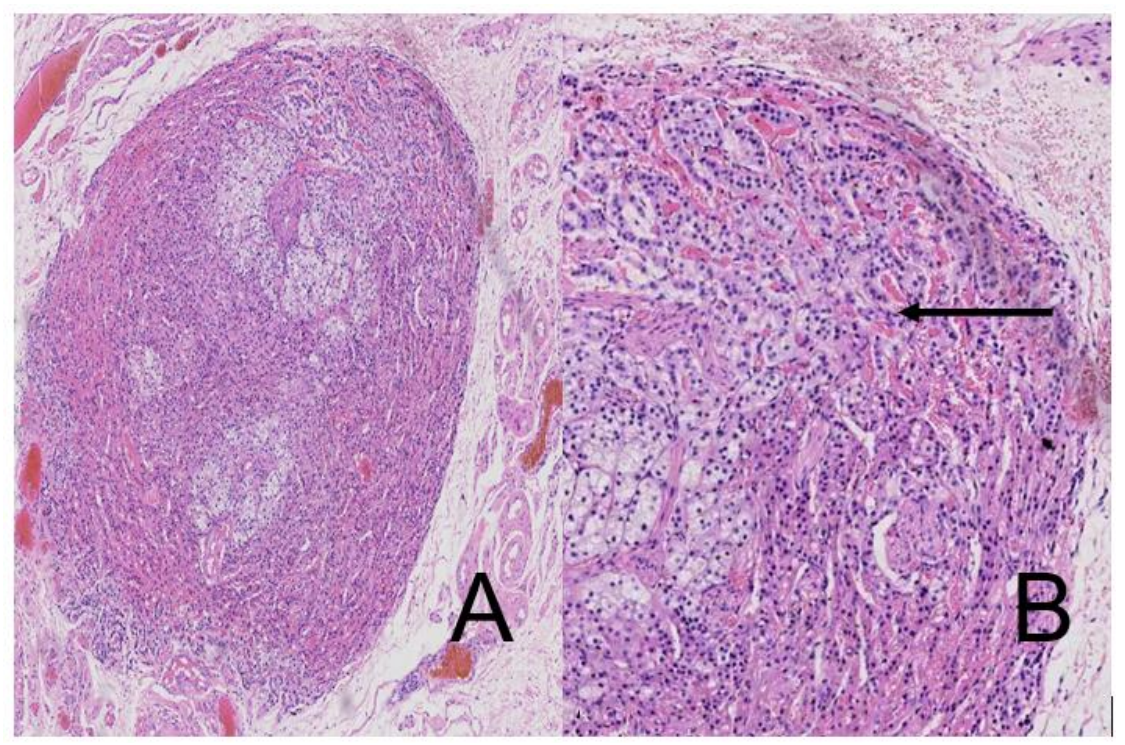

Figure 1. (A) Ectopic adrenal cortex (H\&E staining, magnification $\times 20)$. (B) The spherical band (arrow) (H\&E staining, magnification $\times 40$ ).

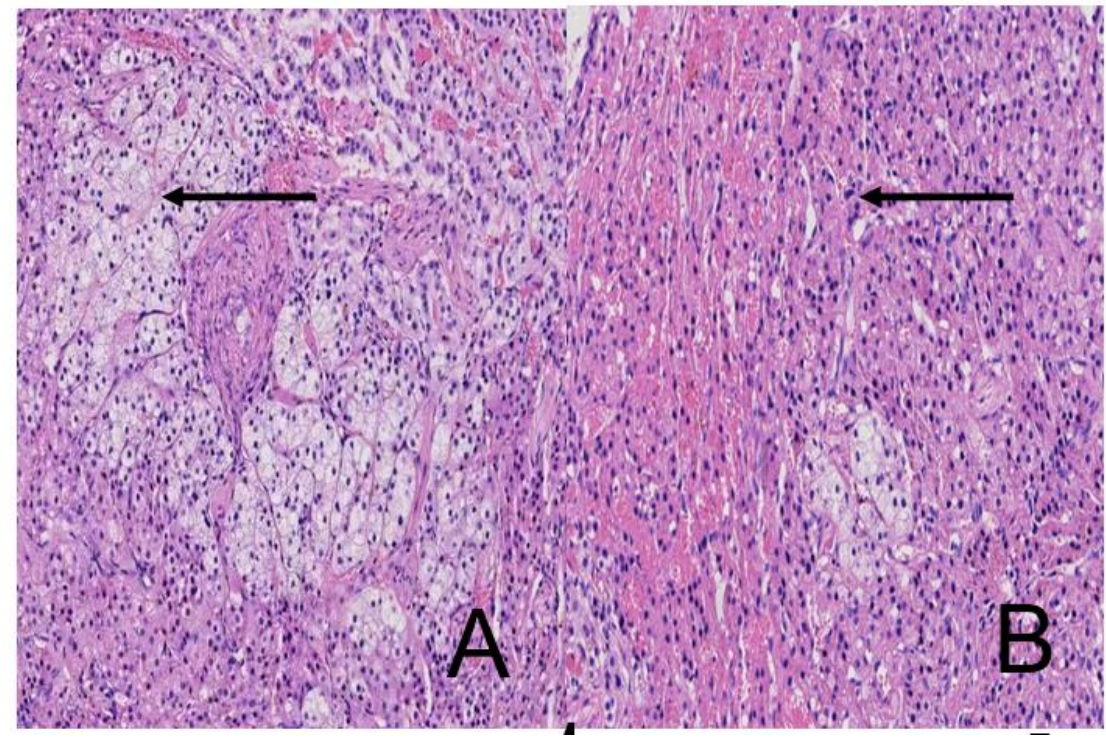

Figure 2. (A) The fascicular zone (arrow) (H\&E staining, magnification $\times 40$ ). (B) The reticular zone (arrow) (H\&E staining, magnification $\times 40)$. 


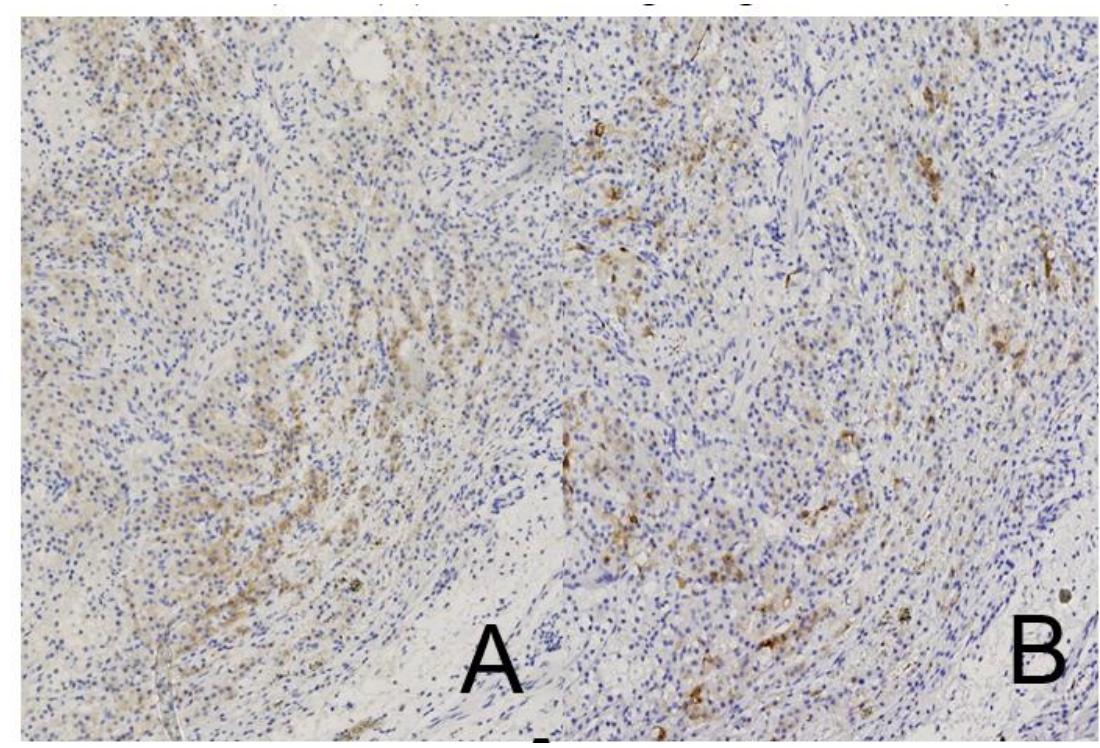

Figure 3. Immunohistochemistry results. (A) Positive for $\alpha$-inhibin (magnification $\times 40$ ). (B) Positive for syn (magnification $\times 40)$.

\section{Discussion}

Ectopic adrenal tissue is most common around the adrenal gland, and also can be seen in the inguinal area, as well as around the testis, spermatic cord, ovary and so on ${ }^{[1-3]}$. This is related to the tissue source of adrenal gland. Adrenal cells have dual embryological origins. The cortex comes from mesoderm and the medulla comes from neural crest ectoderm. The adrenal primordium appears at the 6th week of gestation. It was a cell aggregation on both sides of the dorsal mesenteric root and located in the inner side of the developing gonad. At first, the adrenocortical primordium is not enveloped and is close to the newly formed gonad during its development. The cells in the non-enveloped adrenocortical primordium may be related to the gonad and migrate along the gonad (testis or ovary). If adrenal tissue migrates further, it will develop into a cortical component. As we have seen in our case, only the components of adrenal cortex (zona globosa, zona fasciculata and zona reticularis) were found in the lesions, but no evidence of medullary cells was found.

Ectopic adrenal tissue is defined as the presence of adrenal tissue outside its normal location. According to Anderson et al., ectopic adrenal tissue is more common in children, and its incidence rate in adults is only $1 \%{ }^{[4]}$. Ectopic adrenal tissues are usually small yellow nodules with only cortical components. Microscopically, most of them are well circumscribed nodules with no clear capsule. Ectopic adrenal tissues are the same as normal adrenal tissues, with occasional hemosiderin deposition and few with focal calcification. It is usually found by accident during other surgical operations. The cases of ectopic adrenal tissue in the mesosalpinx are usually found by chance during gynecological surgery in the uterine fibroids, cervical cancer and endometrial cancer. The most common sites of ectopic adrenal gland include testicular appendage, spermatic cord and retroperitoneum. Ectopic adrenal cortex rarely involves fallopian tube. Some scholars also reported that ectopic adrenal tissue was found in pharynx, tonsil, brain, lung, ovary and spine. Ectopic adrenal tissue is mostly incompetent, but like normal adrenal tissue, it can develop into proliferative lesions or tumors, leading to Cushing's syndrome, pheochromocytoma, adrenal cortical tumors and aldosteronism. After bilateral adrenalectomy, patients with Cushing's disease may lead to secondary hyperplasia of ectopic adrenal cortex, which may be one of the causes of recurrence of Cushing's disease. Some scholars also reported rare cases of ectopic adrenocortical adenoma in lung, brain, liver, stomach and spine ${ }^{[5-7]}$. 
However, there are few reports about ectopic adrenal gland in the mesosalpinx. This case of ectopic adrenal gland in mesosalpinx was not found in general but was found by chance under microscope. The patient had no history of normal adrenal gland surgery. Therefore, we believe that ectopic tissue of the ovarian mesentery adrenal gland is caused by the formation of the embryonic adrenal cortical primordium along the descending path of the gonad. Ectopic adrenal gland, like normal adrenal tissue, can produce hyperplasia or tumor, and ectopic tissue has a higher risk of malignant transformation. Most patients had normal adrenal glands, and generally recovered well after operation without abnormal adrenal function. Therefore, ectopic adrenal tissue should be removed no matter where it occurs, whether it is found before or during operation.

\section{Disclosure statement}

The authors declare that there is no conflict of interest.

\section{References}

[1] Ketata S, Ketata H, Sahnoun A, et al., 2008, Ectopic Adrenal Cortex Tissue: An Incidental Finding During Inguinoscrotal Operations in Pediatric Patients. Urol Int, 81(3): 316-319. http://doi.org/10.1159/000151411

[2] Anakievski D, Malinova D, 2019, Heterotopic Adrenal Gland in Undescendent Testis - Case Report. Urol Case Rep, 27(2009):101008. http://doi.org/10.1016/j.eucr.2019.101008

[3] Mendez R, Tellado MG, Somoza I, et al., 2006, Ectopic Adrenal Tissue in the Spermatic Cord in Pediatric Patients: Surgical Implications. Int Braz J Urol, 32(2): 202-207. http://doi.org/10.1590/s1677-55382006000200013

[4] Anderson JR, Ross AH, 1980, Ectopic Adrenal Tissue in Adults. Postgrad Med J, 56(661): 806-808. http://doi.org/10.1136/pgmj.56.661.806

[5] Ren PT, Fu H, He XW, 2013, Ectopic Adrenal Cortical Adenoma in the Gastric Wall: Case Report. World J Gastroenterol, 19(5): 778-780. http://doi.org/10.3748/wjg.v19.i5.778

[6] Yu H, He Y, 2020, Hepatic Adrenal Adenoma-Rare Tumor on Right Lobe of Liver: A Case Report and Literature Review. BMC Surg, 20(1): 128. http://doi.org/10.1186/s12893-020-00780-1

[7] Cassarino DS, Santi M, Arruda A, et al., 2004, Spinal Adrenal Cortical Adenoma with Oncocytic Features: Report of the First Intramedullary Case and Review of the Literature. Int J Surg Pathol, 12(3): 259-264. http://doi.org/10.1177/106689690401200309 